\title{
Paediatric liaison service
}

\author{
Jennie Black, Barry Wright, Christine Williams and Rob Smith
}

\begin{abstract}
Aims and method To discuss the working of a new paediatric liaison service. To review paediatric referrals to a child and adolescent mental health service (CAMHS) 21 months before and 21 months after the establishment of this service.

Results One hundred and eighty-three children were discussed in the 21 months after the new service was set up. There was a rise in referral to CAMHS from 72 to 120 . Non-attendance rates from paediatric referrals also rose. Likely reasons for these changes are discussed. and include an increase in referrals of children with somatisation.

Clinical implications Interdisciplinary liaison appears to carry many advantages, but is likely to increase referral rates to the CAMHS. This has both clinical and resource implications.
\end{abstract}

\section{Establishment and organisation of service}

Inter-team and inter-agency cooperation is recognised as an important building block for all services for children and their families. Regular. open discussions based upon the establishment of good relationships between child health professionals is recognised as being positive (Black et al, 1990; Schwamm \& Maloney, 1997). It allows the development of a degree of common language and shared understanding of the psychosocial issues facing children with physical illness (Vandvik, 1994) as well as their families. The liaison process also allows child mental health professionals to keep abreast with medical issues (Leslie, 1992). It provides a forum to share and discuss ideas (Mattsson, 1976) as well as encouraging a greater understanding of the respective services (Brown \& Cooper, 1987).

Prior to September 1995, though working relationships were good, no formal network existed between paediatric services and child mental health. In that month a paediatric liaison service was established with weekly meetings to provide a forum for consultation, liaison and discussion as well as a review of potential referrals. Paediatricians, a liaison health visitor. a pharmacist and nurses from the paediatric ward already attended a weekly meeting. Following discussion between this service and members of the child and adolescent mental health service (CAMHS), it was mutually agreed that representatives from the CAMHS team (a psychologist. psychiatrist and community psychiatric nurse) should meet the paediatric team at the end of their weekly ward round. The community paediatrician and representatives of the community child health service also attended, as did professionals in training from all disciplines.

Professionals from both teams brought cases for discussion. The meeting began with relevant in-patients and then discussed out-patients. Information was shared, advice offered and referrals between agencies made where appropriate. Summaries of all cases discussed were recorded in a book designed for this purpose. All referrals were followed up in writing. These meetings proved beneficial in providing clearer lines of communication, closer working relationships, increasing levels of mutual respect and two-way learning environment.

\section{Referrals}

York District Hospital offers a service to a population of 270000 , of whom 48000 are under the age of 15 years. This study focused upon referrals from child health to child mental health. Two periods, of 21 months each. were compared. That is, one before and one after the establishment of the paediatric liaison service in September 1995. Information regarding the problems leading to referral was taken from case notes, referral letters and written records of any discussion during liaison meetings. Referrals for deliberate self-harm were excluded from this study, as separate referral routes existed with psychiatric assessment available immediately according to an agreed local protocol and national guidelines (Department of Health and Social Security, 1984).

A comparison of the paediatric referrals to the child mental health team between the two periods showed a rise from 72 to 120 referrals following the establishment of the liaison meetings. As mentioned previously, referrals following deliberate self-harm were excluded, though it is worth noting that the numbers remained fairly constant with a small rise from 53 to 62 over the same comparison periods.

In the period following the establishment of the liaison meetings 183 children were discussed. 75 of these being discussed on more than one occasion. Of the 120 referrals to child mental health services $87(71 \%)$ were recorded as having been discussed prior to referral. The 63 children 
Table 1. Numbers in referral categories

\begin{tabular}{llcc}
\hline Problem leading to referral & $\begin{array}{l}\text { Prior to liaison } \\
\text { meelings } \\
\text { (Dec. 93-Aug. 95) }\end{array}$ & $\begin{array}{l}\text { Following liaison } \\
\text { meelings } \\
\text { (Sept. 95-Apr. 97) }\end{array}$ & $\begin{array}{l}\text { Percentage } \\
\text { change }\end{array}$ \\
\hline Disruptive/anti-social/aggressive behaviour & $10(14 \%)$ & $20(17 \%)$ & $+100 \%$ \\
Over-activity/attention deficit & $2(3 \%)$ & $7(6 \%)$ & $+250 \%$ \\
Problems with scholastic/language skills & $10(14 \%)$ & $6(5 \%)$ & $-40 \%$ \\
Physical/disabillty problems & $11(15 \%)$ & $16(13 \%)$ & $+45 \%$ \\
Non-organic somatic symptoms & $4(6 \%)$ & $12(10 \%)$ & $+200 \%$ \\
Emotional and related symptoms & $6(8 \%)$ & $8(7 \%)$ & $+33 \%$ \\
Problems with peer/family relationships & 0 & $3(3 \%)$ & $+800 \%$ \\
Problems with eating & $1(1 \%)$ & $8(7 \%)$ & $-6 \%$ \\
Soilling/wetting & $16(22 \%)$ & $15(13 \%)$ & $+114 \%$ \\
Autistic features & $7(10 \%)$ & $15(13 \%)$ & $+60 \%$ \\
Other (including psychosis, trauma and & $5(7 \%)$ & $8(7 \%)$ & \\
non-accidental injury) & 72 & 120 & \\
Total & & & \\
\hline
\end{tabular}

Categories are based around Health of the Nation Outcome Scales for Children and Adolescents (Gowers et al, 1999). Notes were not available on two cases.

discussed but not referred had a range of problems, including soiling, behavioural problems and difficulties coping with physical illness. The number of children who did not attend following referral rose from four $(6 \%)$ to 23 (19\%). Over one-third of the non-attenders $(n=8)$ related to referrals for the psychological aspects of physical illness or presumed non-organic somatic symptoms. The numbers in different referral categories are detailed in Table 1.

\section{Discussion}

The development of the relationship between the two services was founded on an open discussion about needs in relation to each service. It had as its bedrock mutual respect. The meeting afforded a forum for discussion of a large number of children. Cases discussed several times were complex or required continued multi-disciplinary input; for example, child protection issues, chronic fatigue syndrome or problems adjusting to a diagnosis of serious physical illness. The increased number of referrals may reflect an increase in awareness of possible psychological distress, as it is unlikely to represent an increase in psychopathology.

Since the commencement of the meetings several benefits have been identified.

\section{Consultation}

This is recognised as an important part of relationships between services (Black et al, 1990; Williams \& Richardson, 1995). Our experience showed that discussion could provide new ideas and support for those already involved with families and often averted the need for formal child mental health involvement.
Liaison about the need for referral ('appropriateness')

Issues concerning approprlateness were not just related to the nature of the referral and the need for child mental health involvement, but also around likely attendance and the prioritisation of work. Certain types of difficulty saw an increase in referral. These included eating problems, which in part reflected a new awareness to eating disorders with the establishment of a specialist eating disorder service within the CAMHS (Roberts et al, 1998). It was also a reflection of some close working between the clinical psychologist and members of the child health team who saw small children with complex feeding problems.

There was an increase in referrals for attention-deficit hyperactivity disorder (hyperkinetic disorder) assessment. A doubling of autism referrals coincided with a push by the Autism Spectrum Disorders Forum in York to arrange quick and comprehensive multidisciplinary assessment.

A fall in certain other referral categories reflected the diversion to other and more appropriate services such as social services, education support services, speech and language therapists or health visitors. This clearly has an impact upon waiting times.

\section{Psychological contribution to unexplained physical symptoms}

Referrals for non-organic somatic symptoms trebled, perhaps reflecting an increased awareness of the psychosocial factors involved with many of these children. The meetings have helped to put family and psychological issues on the agenda with these children (Bingley et al, 1980). 


\section{Urgent cases}

Good relationships fostered within the meetings facilitated the process of urgent referral in both directions.

\section{Non-attendance}

Following the establishment of the liaison meeting non-attendance rates for child mental health appointments rose from $6 \%$ to $19 \%$. The initial low rate of $6 \%$ may have been because many referred families requested child mental health involvement and were more likely to attend as a result. The $19 \%$ is broadly in line with other studies of out-patient attendance rates in child mental health services (Cottrell et al, 1988; Mason et al, 1995).

\section{Joint working}

The CAMHS community psychiatric nurse (CPN) developed a special role in working with children coming to terms with chronic conditions such as diabetes and cystic fibrosis. As a result of the improved liaison the CPN undertook more work on the paediatric ward giving additional input at times of in-patient care. It was acknowledged that intra-team discussion contributed to more joint assessments being carried out; before the meetings only four $(6 \%)$ of allocated cases were jointly assessed, following its establishment 12 $(10 \%)$ cases were jointly assessed.

\section{Communication and consistency of approach}

It has been useful to exchange information in addition to that included in the referral letter. We have found that in a complex case, inter-service communication can be vital in eliminating confusion resulting from inconsistencies in information received.

\section{Cooperation}

The improved networking has had additional benefits facilitating joint ventures such as training, workshops, joint presentations to other professional groups and a new multi-agency forum for discussing children with child health or child mental health problems with colleagues in education and school health services (Williams et al, 1999).

This paper supports previous reports setting out the advantages of good interdisciplinary liaison (Cottrell \& Worrall, 1995). The establishment of, and commitment to, weekly meetings between child health and child mental health professionals has led to improvements in services to children and families.

\section{Acknowledgements}

We thank all those who have helped in collecting the information needed for this paper. We would also like to acknowledge the close cooperation of all members of the respective teams who have made this multi-disciplinary venture so successful. We would also like to thank Ian Partridge for helpful comments and assistance in the preparation of this paper.

\section{References}

Bingley, L., Leonard, J., Hensman S., et al (1980) The comprehensive management of children on a paediatric ward - a family approach. Archives of Disease in Childhood, 55. 555-561.

BLACK, D., MCFADYEN, A. \& BRoster, G. (1990) Development of a psychiatric liaison service. Archives of Disease in Childhood, 66, 1373-1375.

BRown, A. \& COOPER, A. F. (1987) The impact of a liaison psychiatry service on patterns of referral in a general hospital. British Journal of Psychiatry. 160. 83-87.

COTTRELl. D., HIL, P., WALK, D., et al (1988) Factors influencing non-attendance at child psychiatric outpatient appointments. British Journal of Psychiatry. 162, 201-204.

- \& WORRALL. A. (1995) Liaison child and adolescen psychiatry. Advances in Psychiatric Treatment, 1, 78-85.

DEPARTMENT OF HEALTH AND SOCLAL SECURTT (1984) The Management of Deliberate Self-Harm. HM (84)25. London: DHSS.

Gowers, S. G. HARRINGTON, R. C. WHITtON, A. et al (1999) Brief Scale for Measuring the outcomes for emotional and behavioural disorders in children. Health of the Nation Outcome Scales for Children and Adolescents (HoNOSCA). British Joumal of Psychiatry. 174, 413-416.

LEsue, S. A. (1992) Paediatric liaison. Archives of Disease in Children, 67. 1046-1049.

MASON, R. WATTS, E. \& HEWTrSON, J. (1995) Parental expectations of a child and adolescent psychiatric outpatient service. Association of Child Psychology and Psychiatry Review and Newsletter, 17, 313-322.

MATTSSON. A. (1976) Child psychiatric ward rounds on paediatrics. Joumal of the American Academy of Child Psychiatry. 16, 357-365.

ROBErTS, S., FOXTON, T., PARTRIDGe, I., et al (1998) Establishing a specialist eating disorders team. Psychiatric Bulletin. 22, 214-216.

SCHWAMM, J. S. \& MALONEY, M. J. (1997) Developing a Psychiatry Study Group for Community Paediatricians. Journal of the American Academy of Child and Adolescent Psychiatry, 36. 706-708.

VANDVIK, I. H. (1994) Collaboration between child psychiatry and paediatrics: the state of the relationship in Norway. Acta Paediatrica, 83, 884-887.

WILLAMS, C., WRIGHT, B. \& SMTH, R. (1999) CHEAF (Child Health and Education Assessment Forum): a multidisciplinary powwow for children. Psychiatric Bulletin. 23. 104-106.

WILLIAMS, R. \& RICHARDSON, G. (1995) Together We Stand: The Commissioning Role and Management of Child and Adolescent Mental Health Services. London: HMSO.

Jennie Black, Senior House Officer in Psychiatry. Bootham Park Hospital, York; "Barry Wright, Consultant in Child and Adolescent Psychiatry, Lime Trees, Child and Adolescent and Family Unit, 31 Shipton Road, York YO3 6RE; Chris Williams, Clinical Psychologist, Lime Trees, York; and Rob Smith, Consultant Paediatrician, York District Hospital

*Correspondence 